\title{
Selective Webliography for the Physician Writer
}

Mark A. Spasser, PhD, MLS, Jewish Hospital College of Nursing and Allied Health, St. Louis, Missouri

REPRINT REQUESTS:

Mark A. Spasser, PhD, MLS

Chief, Library and Information

Services/Associate Professor

Jewish Hospital College of Nursing

and Allied Health

306 S. Kingshighway Blvd.

MS:90-30-625

St. Louis, M0 63110-1091

Telephone: 314-454-8171

Fax: 314-454-5303

Email: mas1200@bjc.org

Clinical Medicine \& Research

Volume 1, Number 2: 155-158

(C2003 Clinical Medicine \& Research

www.mfldclin.edu/clinmedres
A growing number of Web sites offer resources and tools to assist physicians and scientists in preparing materials for publication. The sites include information about style guides, publishing venues, writing tips and tricks, and general and medical reference. They are intended to facilitate the publishing careers of physician writers.

This webliographical guide is intended to present a selected list of sites that cover the basic issues of writing for publication in professional medical venues. Sites that provide useful information for scientific authors who want either help with their writing or information resources that are "ready-at-hand" (analogous to the physically located reference library). The subject headings are intended to offer a division of resources into heuristically useful categories. Whenever possible, this selective webliography focuses on free, quality online materials. The primary purpose of this webliography is to assist the physician and researcher with the task of identifying, analyzing and utilizing quality sites, when bombarded with hundreds of sites listed by gateways and directories, and in results from search engine queries. 
A selective list of writing-related resources and tools freely available online includes:

\section{PORTALS}

MedWebPlus

http://www.medwebplus.com ${ }^{1}$

A free service for locating health science information quickly and easily. The "Publishing and Publications" section contains a variety of writing-related links, in such areas as abbreviations, clinical protocols, congresses and case studies. MedWebPlus also includes an extensive alphabetical directory to journals and associations.

MEDWEB@Emory University

http://170.140.143.133/MedWeb/

Sites for Writing include Roster of Physician Writers, European Medical Writers Association, various chapters of the American Medical Writers Association and the National Association of Science Writers, all of which collocate some information resources for physician writers.

American Medical Writers Association

Delaware Valley Chapter

http://www.amwa-dvc.org/toolkit/index.shtml

"Toolkit for New Medical Writers" was designed for an audience, including medical writers with scientific or medical degrees, that have worked in the field, or in health sciences administration. Those who have degrees in English or Journalism, work in communications, and write about health and/or medical topics, will also find this site beneficial. Accordingly, while many resources are directly applicable to scientific medical writing, some are more relevant to marketing medical writers.

Writers Write ${ }^{\circledR}$ - Medical Writing

http://www.writerswrite.com/medical/medlink.htm

"Resources for Medical Writers" are grouped into the following subject headings: general reference, books, dictionaries/encyclopedias, employment, government medical resources, medical company directories, medical industry resources, medical news, medical reference resources and organizations.

Instructions to Authors in the Health Sciences http://www.mco.edu/lib/instr/libinsta.html

Perhaps the most important resource in this group, is this site published by the Raymon H. Mulford Library of the Medical College of Ohio. The site consists of 3,500+ links to journals in the health and life sciences. The links are to "primary sources" (publishers or organizations with editorial responsibilities for the titles). This Medical College of Ohio site is a great convenience to all scientific medical writers.

\section{STYLE GUIDES}

As anyone who has submitted articles for publication in almost any journal knows, each journal has a required format for manuscripts submitted, including a format for bibliographical references.

\section{Uniform Requirements for Manuscripts Submitted to} Biomedical Journals

According to the International Committee of Medical Journal Editors (ICMJE), "A small group of editors of general medical journals [subsequently known as the Vancouver Group] met informally in Vancouver, British Columbia, in 1978 to establish guidelines for the format of manuscripts submitted to their journals. Its requirements for manuscripts including formats for bibliographic references developed by the National Library of Medicine, were first published in 1979."

Multiple editions of the Uniform Requirements have been produced, and the entire document was revised in 1997. Sections are continually updated as needed.

Interestingly, more than one site publishes the Uniform Requirements. For example, the page on the Canadian Medical Association site (http://www.camj.ca) was last updated on "10 March 2002," whereas the page on the ICMJE site (http://www.icmje.org/index.html) was updated "October 2001." (Both pages were accessed December 15, 2002). This discrepancy may not be substantively meaningful, however, when using Web-based information, one must always check its currency.

National Library of Medicine Recommended Formats for Bibliographic Citation: Supplement: Internet Formats http://www.nlm.nih.gov/pubs/formats/internet.pdf

This is a PDF file (the freely available Adobe Acrobat Reader software is needed to view this document) that describes the recommended formats for electronic references. As noted in the discussion of the Uniform Requirements above, this Supplement effectively functions as an update to the Uniform Requirements.Uniform Requirements.

\section{Publication Manual of the American Psychological Association, 5th ed. http://www.apastyle.org/}

Journals publishing materials at the intersection of the social sciences/psychology/education and medicine, may require manuscripts submitted in American Psychological Association (APA) Style. While the complete APA Manual is not available online, APA does make the following sections freely available on the APA Style Web site: electronic references formats, style tips, and ethics of publication. Moreover, several sites assist with using APA style (although users must ensure that the aids refer to 2002 5th ed.-a vari-

\begin{tabular}{llll}
\hline $156 \quad C M \& R$ & 2003 : 1 (April) & Spasser
\end{tabular}


ant on the necessity to establish the currency of information). For example, a user's guide to the APA Manual 5th ed. is available at:

http://www.jhconah.edu/library/guides_links_toc.html

NOTE: Two other style guides may be interest to some physician writers:

1) Council of Biology Editors Scientific Style available at: http://writing.colostate.edu/references/sources/cbe/index.cfm 2) American Sociological Association (ASA) Style Guide (abbreviated guide to ASA style) available at:

http://www.calstatela.edu/library/bi/rsalina/asa.styleguide.html

\section{MEDICAL REFERENCE}

There are many medical references freely available online. A couple of the portals discussed previously have medical reference sections. In this discussion only a few of the many resources available are mentioned.

\section{whonamedit.com}

http://www.whonamedit.com/

This site is a biographical dictionary of medical eponyms that purports to offer a complete survey of all medical phenomena named for a person, with a biography of that person. According to the site's editors (page retrieved December 15, 2002), whonamedit.com contains 6117 eponyms linked to 2847 persons.

\section{GUIDE FOR THE CARE AND USE OF LABORATORY ANIMALS}

http://bob.nap.edu/html/labrats/

The NAP site has several thousand books and reference works (many of which are health-related) issued under the auspices of some governmental agency or department available free. For scientific and/or clinical medicine research that involves the use of laboratory animals, this National Academies Press (NAP) publication describes guidelines and practices promulgated by the authority Institute of Laboratory Animal Resources, Commission of Life Sciences, National Research Council.

\section{Institutional Review Boards (various)}

When human subjects are involved, each college or university requires that the research be peer reviewed by an Institutional Review Board (IRB) to ensure the safe and ethical treatment of the experimental subjects. Accordingly, while the issues, problems and safeguards are universal, each IRB implements procedures specific to a given institution. For example, IRB information for the Washington University Medical School (St. Louis) is available at: http://medweb.wustl.edu/IRB-educate/menu_med.html
Medical Texts/References in the Public Domain (various)

Several sites make several classic, public domain medical texts freely available.

1) University of Pennsylvania's Online Books Page available at: http://digital.library.upenn.edu/webbin/book/subjectstart?R

2) FreeBooks4Doctors available at:

http://www.freebooks4doctors.com/fb/index.htm

3) Bartleby (includes dictionaries, thesauri, "Gray's Anatomy," and many other useful references) available at: http://www.bartleby.com, and selected publications of the 4) National Academies Press available at: http://www.nap.edu/books/

\section{Medical Search Engines}

While a discussion of Web search engines is well beyond the scope of this webliography, there are search engines that focus exclusively on health sciences and biomedical information resources. A group of such medical information search tools are available at:

1) http://medmark.org/engines.htm

2) http://www.searchenginewatch.com/links/medical.html

\section{NLM Gateway}

http://gateway.nlm.nih.gov/

The target audience for the Gateway is the researcher writer wanting "one-stop-shopping" for many of the National Library of Medicine's (NLM) information resources. The NLM Gateway presents a single interface that lets users search in multiple retrieval systems including:

1) MEDLINE/PubMed

2) LOCATORplus

3) Lonesome Doc

4) Other specialized health science databases

\section{GENERAL REFERENCE}

The number of vetted and high-quality general references (many of which, of course, are writing related) is staggering, so the discussion is limited to a few highly regarded reference portals. However, these reference Web sites (and many others) collectively provide physician writers with every conceivable writing tool, from dictionaries and thesauri, to illustrated encyclopedia, language usage guides, and quotation sourcebooks.

OneLook ${ }^{\circledR}$

http://www.onelook.com/

The OneLook site is a portal to almost every kind and type of dictionary imaginable, including general, computing, science, technology and medicine. Medical dictionaries and glossaries indexed by OneLook include: Alzheimer's Association Medical Glossary, Dictionary of Cancer Terms, Eye Dictionary, Glossary of Drug Terms, Alternative Medicine, and dozens of others. 
Librarians' Index to the Internet (LII)

http://lii.org/

Offered by The Library of California, the LII is a gateway to vetted Web sites that cover every imaginable subject and topic. Health \& Medicine is subdivided into such subsections as 'Diseases, Nutrition, Conditions,' and more. These are human-evaluated sites that the author/clinician can trust to be authoritative, unbiased, and relatively current.

ReferenceDesk.org

http://www.referencedesk.org/

Called by many to be the Internet's best reference source, this portal is directed largely at a research-oriented audience, with sections on finding people and quotations, encyclopedias, English tools, government resources, magazines and newspapers, and, of course, medical and health resources.

\section{MISCELLANEOUS}

Internet Tutorial for the Medic

http://www.vts.rdn.ac.uk/tutorial/medic

This is a tutorial directed toward the physician who is new to searching online for health-related information. While it has a definite British flavor, it offers many useful suggestions and tips to users for locating the cornucopia of quality information resources freely available on the Web.

\section{Content Evaluation Guidelines}

http://www.mlanet.org/resources/userguide.html\#3

The Medical Library Association (MLA) publishes a succinct set of guidelines for evaluating information and sites found on the Web. While there are many such guides for evaluating Internet information, this user guide is authoritative, clear and applies equally well to all information resources, whether electronic or print. Putting MLA's user guide to immediate use, while this webliography does contain a few ".com" sites. These sites should always be carefully evaluated, especially with regard to the sponsorship criterion.

\section{Alerting Services (various)}

As anyone who must attempt to keep current on any aspect of medical literature knows, it is an increasingly difficult task. That is where these Web-based tools come in. By specifying subject terms, physicians and scientists are updated on newly published literature relevant to their specialty and research interest. All that is required is a valid email address. Current awareness services include:

1) PubCrawler available at:

http://www.pubcrawler.ie/

2) BioMail available at:

http://www.biomail.org/
Lonesome Doc

http://www.nlm.nih.gov/pubs/factsheets/loansome_doc.html

For the unaffiliated (or remotely located) physician writer, this National Library of Medicine document fulfillment service offers a convenient way to obtain journal articles found during searches of the MEDLINE/PubMed database, from one of the alerting services mentioned previously, or through the NLM Gateway. Available to users with an established agreement with a participating medical library (i.e., the ordering library), the Lonesome Doc document delivery service enables users to order articles from lists of citations retrieved from PubMed and the NLM Gateway by sending requests to the ordering library for the full-text documents.

Due to the diversity and number of Web-based writing resources and tools, this webliography can only provide a suggestive core list, and is not intended to be comprehensive. Moreover, because the Web is constantly growing and changing, it behooves physicians and scientists to regularly check for new resources (see Alerting Services). Finally, track changes to valued resources, by using the following free services:

1) Watchit.us available at:

http://www.watchit.us

2) TrackEngine available at:

http://www.trackengine.com/servlets/com.nexlabs.trackengine.ui.Login

\section{REFERENCES}

1. Visit http://www.colby.edu/web_class/URL/anatomy.html for a clear and extensive discussion of the anatomy of Uniform Resource Locators (URLs). To anticipate the discussion and to avoid confusion, 'www' is often, but not always, a part of the URL, depending on whether it is part of the server name. Also, case and punctuation matter; while a Web page can sometimes be accessed using slightly different URLs, to be safe, always enter the URL exactly as it appears. 